\title{
The Effect of Nanogold-Nanosilver to Boost Immunity of People Affected by COVID-19 with Comorbidities of Diabetes Mellitus
}

\author{
Fatimatuzzahro $^{1}$, Titik Taufikurohmah ${ }^{2}$ \\ ${ }^{1,2}$ Department of Chemistry, Faculty of Mathematics and Natural Sciences, Universitas Negeri Surabaya, Indonesia
}

\begin{abstract}
COVID-19 virus has spread almost all over the world, including Indonesia until now. COVID-19 in people with diabetes mellitus have a risk of exacerbating symptoms. Diabetes is a disease caused by high blood sugar levels. Nanogold has a very strong anti-oxidant capability, while nanosilver has anti-bacterial properties. In this research, nanogold-nanosilver was presented in the form of health drinking water packaged in $1 \mathrm{~L}$ bottles and could be consumed directly. This research aimed to determine the effect of nanogold-nanosilver to boost the immunity of people affected by COVID-19 with comorbidities of diabetes mellitus on Jl. Merr Surabaya to Juanda highway, Surabaya City. The method in this research was the lecture method at the beginning of the activity. Health Drinking Water Materials were distributed once a week, namely on Friday, July 31 to August 28, 2020. The sampling technique used accidental sampling with a total sample of 100. Interviews recording medical conditions were collected and analysed. The results obtained were a decrease in blood sugar levels to normal in patients with diabetes mellitus and the immunity of the participant volunteers was well maintained in the midst of the COVID-19 pandemic. The age group under 39 years had the greatest decrease in blood sugar levels. In accordance with the research results, Nanogold-Nanosilver Health Drinking Water has succeeded in increasing and maintaining the immunity of participants who have comorbidities with diabetes mellitus and are affected by COVID-19. Besides, the participant survived not to be affected to COVID-19 during activities.
\end{abstract}

KEYWORDS: COVID-19, Diabetes Mellitus, Immunity, Nanogold, Nanosilver

\section{INTRODUCTION}

The coronavirus outbreak due to the SARS-CoV-2 virus has infected more than 97 million people in the world. Wuhan City, China was the place where this outbreak first appeared and is now a serious health problem in the world [1]. Based on the data of World Health Organization [2], Indonesia has currently confirmed 557.877 cases and it is still increasing. COVID-19 is a highly contagious and rapidly spreading disease, the severity varies from a mild flu illness that resolves itself to fulminant pneumonia, respiratory failure and death. [3]. Elderly people or people suffering from chronic (comorbid) diseases have a greater chance of being infected with COVID-19. Chronic diseases include chronic respiratory disorders, cardiovascular disease, diabetes mellitus, and hypertension. Diabetes mellitus is the second most common comorbidity of $8 \%$ of cases after hypertension [4].

Diabetes mellitus has currently affected 422 million people worldwide [5]. Diabetes mellitus is a chronic disease due to inadequate insulin produced by the pancreas or insulin can't work optimally [6]. COVID-19 and diabetes mellitus are diseases associated with acute and chronic inflammation. Both of these disease conditions are prognoses that worsen the life chances of COVID-19 sufferers with comorbidities of diabetes mellitus. The COVID-19 virus entry port is a unique surface glycoprotein on ACE2, the "spike". ACE2 in type II alveolar cells of the lungs is abundant. If the amount of ACE2 in COVID-19 patients is excessive, the severity of the disease suffered by the patient also increases and it can cause ARDS, damage to the liver, heart, kidneys, and even cause death [7]. Patients with COVID-19 and diabetes mellitus tend to have a three-fold greater risk of death than patients in general ( $7.3 \%$ versus $2.3 \%)[8]$.

Nanotechnology is an extraordinary matter in today's field of research. The nanotechnology approach is concerned with the design, synthesis, and manipulation to create structures of 1-100 nm-sized particles which are eventually called nano-sized particles or nanoparticles [9]. Nanogold is currently used in various fields of science and technology, such as electrical engineering, catalysis, cosmetics, medicine, and pharmacology [10]. In vitro test of nanogold has activity to reduce free radicals. The artificial free radical used is divinyl picryl hydracil (DPPH). The anti-oxidant capability of nanogold is powerful, which is 10 times vitamin $\mathrm{E}$ and 5 times vitamin $C$ at the same concentration. This high anti-oxidant activity causes nanogold to be very well used to increase immunity [11]. Nanogold is a very promising candidate to detect pathogens, including viruses [12]. Chinese researchers have developed new gold nanorods as a class of peptide inhibitor-based that carefully target the coronavirus S protein and slow the activity [13]. Nanogold 


\section{International Journal of Current Science Research and Review}

ISSN: 2581-8341

Volume 04 Issue 07 July 2021

DOI: 10.47191/ijcsrr/V4-i7-02, Impact Factor: 5.825

IJCSRR@ 2021

www.ijcsrr.org

can increase the activity of fibroblast cell proliferation and increase collagen biosynthesis [14]. In vitro and in vivo, toxicity tests showed that nanogold is safe for the body [15].

Nanosilver or silver nanoparticles have been used in food packaging, materials, dietary supplements, textiles, electronics, household appliances, cosmetics, medical devices, water disinfectants, and indoor sprays as their excellent anti-bacterial and plasmonic properties [16]. The FDA (Food and Drug Administration) approves nanosilver for medical use in wound healing due to its anti-microbial properties [17]. Research has found that nanosilver can bind to HIV particles, thereby inhibiting the virus from binding to host cells. Besides, nanosilver can inhibit viral DNA or RNA replication [18]. In the case of diabetes mellitus, nanogold has enzymatic activity that can increase the activity of pancreatic cells to produce insulin [14] and nanogold can prevent oxidative stress that is the main cause of hyperglycemic conditions [19], while nanosilver can increase insulin levels, reduce insulin resistance, reduce lipid profiles and inflammatory markers. Thus, it can be considered that nanosilver has effective anti-diabetic activity [20].

With the support of various nanogold and nanosilver literature, the researchers are sure and they conducted research by providing health drinking water containing nanogold-nanosilver to be distributed to research participants, such as the community located on Jl. Merr Surabaya headed to Juanda highway, Surabaya City with the research target of participants affected by COVID-19 with comorbidities of diabetes mellitus.

\section{MATERIAL AND METHOD}

\subsection{Material}

The manufacture of Health Drinking Water in this research used a compound $\mathrm{HAuCl}_{4} 1000 \mathrm{pm}$ that needs to be synthesised into the form of nanomaterial $\mathrm{Au}$ (nanogold) and compound $\mathrm{AgNO}_{3} 1000 \mathrm{ppm}$ was needed to be synthesised into the form of nanomaterial Ag (nanosilver). Both for nanogold and nanosilver are reduced using sodium citrate first. For the tools, it was used beakers, measuring cups, measuring flasks, watch glasses, analytical scales, magnetic stirrer, and hot plates. After obtaining the nanogold and nanosilver materials of $20 \mathrm{ppm}$ each. Furthermore, dilution was carried out using distilled water to $2 \mathrm{ppm}$. The ratio of nanogold and nanosilver solution was 4:1, then put in a $1000 \mathrm{~mL}$ or $1 \mathrm{~L}$ of bottle.

\subsection{Method}

This research used the lecture method at the beginning of the activity or the opening of the activity. The lectures used were interactive lectures so that people have an interest and sense of responsibility in completing activities. Health Drinking Water materials were distributed to research participants, such as people who lived in Surabaya city, on Jl. Merr Surabaya to Juanda highway once a week, on Fridays from July 31 to August 28, 2020. Drinks were consumed with a dose of 150-300 mL or half to 1 cup and repeated 1-3 times a day. Interviews recording medical conditions were collected and analysed. The development of health conditions can be seen from positive changes, it means the blood sugar levels of people with diabetes mellitus change to normal.

\section{RESULT}

\subsection{Synthesis Result}

The results of the synthesis were nanogold and nanosilver with a concentration of $20 \mathrm{ppm}$ which were diluted to a concentration of $2 \mathrm{ppm}$ by means of $100 \mathrm{~mL}$ of nanogold inserted into a $1000 \mathrm{~mL}$ bottle, then added water up to $1000 \mathrm{~mL}$. The same treatment was also carried out for nanosilver. After that, each nanogold and nanosilver with a ratio of 4:1 were mixed homogeneously and put in a $1000 \mathrm{~mL}$ or $1 \mathrm{~L}$ bottle labeled as Health Drinking Water. Nanogold and nanosilver were tasteless and non-toxic colloids. Nanogold and nanosilver are safe to drink [21].

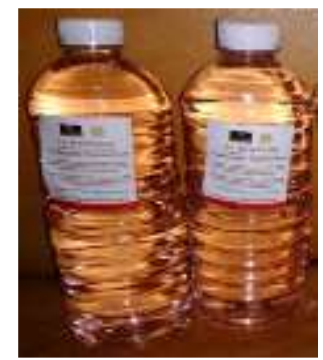

Figure 1. Nanogold-Nanosilver Health Drinking Water 


\section{International Journal of Current Science Research and Review}

ISSN: 2581-8341

Volume 04 Issue 07 July 2021

DOI: 10.47191/ijcsrr/V4-i7-02, Impact Factor: 5.825

IJCSRR@ 2021

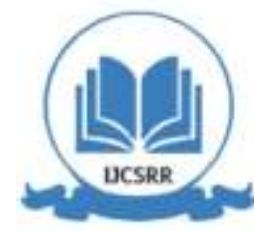

www.ijcsrr.org

Figure 1 shows that Nanogold-Nanosilver Health Drinking Water has been packaged in $1000 \mathrm{~mL}$ or $1 \mathrm{~L}$ bottles with a label containing the benefits and how to consume it.

\subsection{Clinical Test Result}

The results of the research included the results of clinical trials with an average of 100 participants per meeting, namely people affected by COVID-19 on J1. Merr, Surabaya with various age groups, both male and female. It was found that data on the disease and complaints of participants also gradually recovered during the treatment. These diseases and complaints include diabetes mellitus, hypertension, rheumatism, cough, flu, ulcers, tingling, and dizziness revealed in this clinical trial. Of the 100 participants in each meeting who took part in this activity, the number of participants with comorbidities of diabetes mellitus (blood sugar level of more than $200 \mathrm{mg} / \mathrm{dl}$ ) was an average of 12 people per meeting. The participants experienced recovery until they reached normal blood sugar levels gradually during clinical trials from July 31 to August 23, 2020.

Table 1. Data on the number of participants with comorbidities with diabetes mellitus

\begin{tabular}{llllll}
\hline Time & Week 1 & Week 2 & Week 3 & Week 4 & Week 5 \\
\hline Number of participant & 100 & 102 & 106 & 95 & 97 \\
Diabetes & 20 & 17 & 10 & 9 & 4
\end{tabular}

Based on Tabel 1, The number of participants who attended the activity was erratic and the number of participants who had comorbidities with diabetes mellitus decreased along with the length of treatment time.

In Table 2, the recovery process could be observed from the decrease in blood sugar levels of participants with comorbidities of diabetes mellitus who conducted routine examinations every week.

Table 2. Blood sugar levels of participants affected by COVID-19 with comorbidities of diabetes mellitus

\begin{tabular}{|c|c|c|c|}
\hline \multirow{2}{*}{ Time } & \multicolumn{3}{|c|}{ Average Blood Sugar Level/ COVID-19 Description (+/-) } \\
\hline & Above 60 years old (6 people) & 40-59 years old ( 4 people) & Under 39 years old ( 2 people) \\
\hline Week 1 & $550 /-$ & $430 /-$ & $230 /-$ \\
\hline Week 2 & $485 /-$ & $360 /-$ & $210 /-$ \\
\hline Week 3 & $375 /-$ & $325 /-$ & $190 /-$ \\
\hline Week 4 & 290/ - & $275 /-$ & $165 /-$ \\
\hline Week 5 & $200 /-$ & $170 /-$ & $140 /-$ \\
\hline
\end{tabular}

Based on Table 2, it can be seen that the number of participants with comorbid diabetes mellitus was 12 people with a description of the age above 60 years of 6 people, ages between 40-59 years of 4 people, and age under 39 years of 2 people. The highest average blood sugar level was the group of participants aged over 60 years, followed by the group of participants aged 40-59 years, and the lowest average blood sugar level was the group of participants under 39 years of age.

Data on Respondents Average Blood Sugar of Clinical Test with

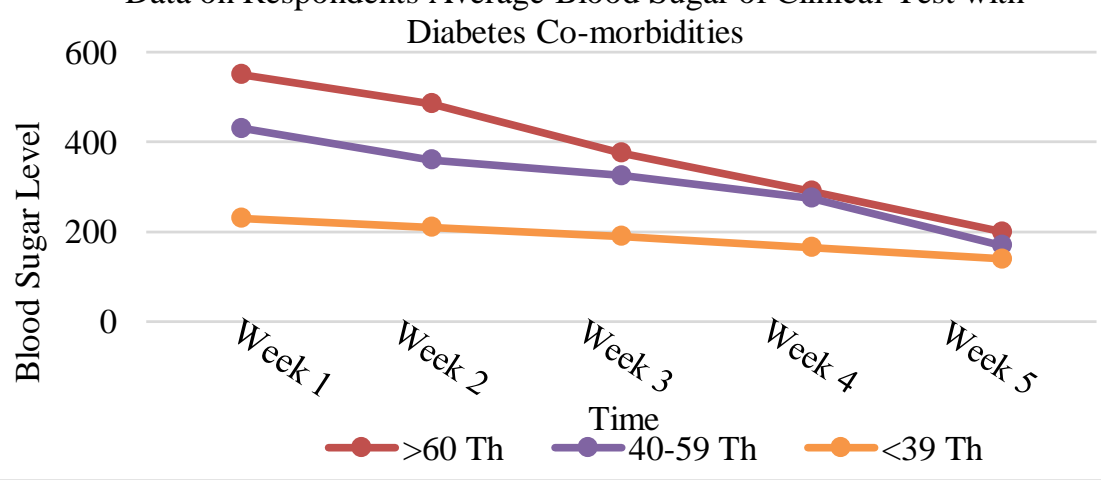

Figure 2. Graph of Decrease in Average Blood Sugar Levels of Participants Affected by COVID-19 with comorbidities of Diabetes Mellitus 


\section{International Journal of Current Science Research and Review}

ISSN: 2581-8341

Volume 04 Issue 07 July 2021

DOI: 10.47191/ijcsrr/V4-i7-02, Impact Factor: 5.825

IJCSRR@ 2021

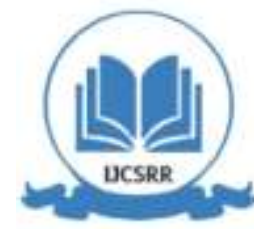

www.ijcsrr.org

Figure 2 is a graph of the average decrease in blood sugar levels of participants affected by COVID-19 with comorbidities of diabetes mellitus. It can be seen that the age group under 39 years old had the greatest decrease in blood sugar levels, indicated by the point of the green curve is at the bottom at week 5 , whereas the age group above 60 years was indicated by the point in the red curve is at the top at week 5 .

Based on the graph shown in Figure 2, the curve decreases along with the length of treatment time. This was in accordance with the literature that nanogold plays a role in enzymatic activity in increasing the activity of pancreatic cells which produce the hormone insulin that can decompose blood sugar into energy [14]. Thus, nanogold-nanosilver plays a role in controlling blood sugar levels into normal blood sugar levels in participants with comorbidities of diabetes mellitus during clinical trials.

\section{DISCUSSION}

\subsection{The Relation between Nanogold-Nanosilver toward the Immune of People Affected by COVID-19}

Nanotechnology can be defined as the design and application of multiple materials and devices in which at least one dimension is less than 100 nanometers. In the medical field, the application of nanotechnology is well-known as nanomedicine. It consists of the use of nanomaterials for the diagnosis, treatment, control and prevention of disease [22]. Several metal nanoparticles are known to have a broad spectrum of action against viruses and other microorganisms [23]. Due to its unique optical properties, stability, and biocompatibility, gold nanoparticle is the most commonly used nanoparticle in viral diagno stic detection [15]. The application of nanogold in the colorimetric detection of SARS-CoV has been reported [24]. S.F. Ahmed et al. (2020) conducted a research using nanogold against RNA viruses, the results obtained showed that nanogold was able to enhance the anti-viral activity of drugs, which represented a potential platform against SARS-CoV-2 [25]. In a research conducted by Dykman \& Khlebtsov (2011), they revealed that nanogold served as an antigen carrier that was proven to stimulate the phagocytic activity of macrophages and affect the performance of lymphocytes which are responsible for the immune modulating effect. The effect of nanogold on lymphocyte performance was demonstrated by a ten-fold increase in proliferation. It indicates that nanogold acts directly in the destruction of pathogens [15].

Several studies have shown that nanosilver acts as an effective anti-viral against various human pathogenic viruses such as Respiratory Syncytial Virus (RSV), influenza, norovirus, hepatitis B, and HIV [26]. In a research conducted by Jeremiah et al. (2020), they proved that nanosilver effectively inhibited extracellular SARS-CoV-2 to protect target cells from infection and a pseudovirus entry test revealed that nanosilver interfered with virus entry [27]. Nanosilver has also been shown to have strong anti-microbial properties. The anti-microbial properties of nanosilver cause these nanomaterials to become popular. Thus, they are widely used as various products [28]. Nanosilver is a soft acid that interacts with bacterial cells containing soft bases (such as sulfur and phosphorus). The anti-bacterial mechanism of nanosilver is that the nanosilver in the bacterial cell will release silver ions and the silver ion will attach to the protein thiol group, which causes the biological process of the bacterial cell to be disturbed [29]. The oxidation reaction between the silver ion with the oxygen and hydrogen atoms of the thiol group will produce a disulfide bond. Disulfide bonds can interfere with DNA replication which causes inhibition of bacterial growth, thereby causing apoptosis [30].

This Health Drinking Water with the combination of Nanogold-Nanosilver succeeded in maintaining the immunity of the participants who took part in the activity from July 31 to August 28 2020. Thus, participants were not affected by COVID-19, even though in Surabaya on July 31, 2020 there were 8691 cases and on August 28, 2020 it reached 11,873 cases [31]. It showed that cases in Surabaya had increased, causing a very large risk of contracting COVID-19, but this was not experienced by participants who took part in this research.

\subsection{The relation between Nanogold-Nanosilver and Diabetes Mellitus}

Metal nanoparticles such as nanogold and nanosilver seem to have promising potential in the prevention and treatment of disorders caused by excessive formation of ROS (Reactive Oxygen Species) [32]. Nanoparticles are increasingly used for various biomedical applications due to their outstanding biophysical properties and can be adapted depending on their size and shape [33]. Opris et al. (2017) conducted a research by synthesising and screening the anti-diabetic activity of nanogold functionalised with Sambucus nigra L. extract in Wistar albino male rats. The research demonstrated a reduction in blood glucose levels and most importantly reduced inflammation and oxidative stress caused by hyperglycemia and no acute liver toxicity in the biogenic nanogold treated group was reported. The results obtained suggest that very small doses of nanoparticles are sufficient to increase 


\section{International Journal of Current Science Research and Review}

ISSN: 2581-8341

Volume 04 Issue 07 July 2021

DOI: 10.47191/ijcsrr/V4-i7-02, Impact Factor: 5.825

IJCSRR@ 2021

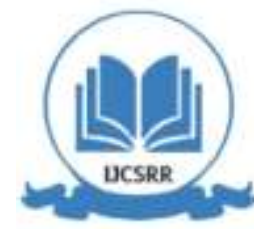

www.ijesrr.org

the anti-oxidant potential of cells and to regulate inflammatory reactions [34]. Several researchers published reports on the delivery of nanogold-based drugs. Nanogold is a unique metal nanoparticle. It has been shown to be an efficient and stable insulin delivery carrier. The insulin nanogold formulation protects insulin from degradation and increases its absorption in the ileum and hence reduces blood glucose concentration [35]. Although nanogold works efficiently as insulin carriers, it is also studied in diabetes management for its anti-oxidant effects. Anti-oxidants from nanogold play an important role in treating the etiology of diabetes and its complications [36]. Nanogold could increase insulin, glutathione peroxide and enzyme activity of catalase and superoxide dismutase (SOD) $(\mathrm{p}<0.001)$ in streptozotocin-induced diabetic rats treated with nanogold. These enzymes play a major role in the scavenging of endogenous hydrogen peroxide and collectively cause a reduction in oxidative stress in hyperglycemia [37].

Nanosilver is widely used in the medical sector because of its superior chemical stability, high conductivity, catalytic activity, and localised surface plasma resonance [38]. Nanosilver can be utilised as an intrinsic therapeutic agent because silver has anti-bacterial and anti-inflammatory properties that support healing of chronic wounds [39]. In addition, nanosilver has a broad anti-bacterial spectrum and shows excellent potential for wound healing in diabetic conditions [40]. The anti-bacterial potential of nanosilver acts through the respiratory enzyme inhibitory pathway and alters the cell wall and DNA of bacterial microbes [41]. Biologically, synthesised nanosilver can effectively cure diabetes, as well as improve kidney function in animal models [42]. Research conducted by Agarwal et al. (2018) synthesised nanosilver using fresh lemongrass leaf extract carried out with a series of in vivo experiments. It was proven that nanosilver has anti-diabetic activity. Thus, nanosilver can act as a potential drug candidate for the treatment of diabetes that is not dependent on insulin [43].

The application of nanotechnology in the treatment of diabetes is a promising approach that needs to be explored extensively. Advances in biomaterials and engineering, improved glucose monitoring, and insulin delivery systems will be critical next steps in improving diabetes treatment. The provision of Health Drinking Water with a combination of nanogoldnanosilver can control the blood sugar levels of participants with comorbidities of diabetes mellitus become normal during the pandemic season.

\subsection{The Relation between Diabetes Mellitus and COVID-19}

People with diabetes mellitus tend to be more easily infected with viruses and bacteria, including things that affect the respiratory tract [44]. Disorder of leukocyte function from phagocytosis (immune disorders) or the so-called lazy leukocyte syndrome is a mechanism responsible for this tendency. This situation facilitates the possibility of SARS-CoV-2 infection in people with diabetes mellitus [45]. Microangiopathy in diabetes mellitus also impairs lung compliance that affects gas exchange. This damage can lead to the proliferation of several respiratory pathogens, including SARS-CoV-2 [46]. Respiratory changes in diabetic patients that affect lung volume and lung diffusion capacity [47]. In a research conducted by Muniyappa and Gubbi (2020), they summarised the potential mechanisms by which diabetes mellitus increases SARS-CoV-2 morbidity and mortality: (i) increased cellular binding affinity and efficient viral entry, (ii) decreased viral clearance, (iii) decreased T-cell function, and (iv) increased susceptibility to hyper-inflammation and cytokine storm [45]. Glycemic variability is a prognostic factor in diabetic patients with COVID-19 infection. Hyperglycemia worsens outcomes by cytokine storm processes, endothelial dysfunction, and multiple organ injury [48]. In the lung, which is the main target of COVID-19, hyperglycemia causes a rapid decline in spirometry function, especially forced expiratory volume decreased in 1 second and forced vital capacity [49]. In the hyperglycemic state, there is an increase in the concentration of glucose in the respiratory epithelium which can impair its innate immune capacity [50]. Hypoglycemia also increases cardiovascular mortality by maximising pro-inflammatory monocytes and increasing platelet aggregation [51]. Severe hypoglycemia that can occur with tight glycemic control can worsen mortality [52]. Therefore, a chronic hyperglycemic state and a chronic inflammatory state were two pathophysiological elements of immunosuppression that occur in people with diabetes mellitus with a higher risk of COVID-19 infection, and also represent an increased risk of death [3].

In a research investigating the cellular and molecular mechanisms responsible for the increased risk of individuals with diabetes mellitus for COVID-19 is ACE2 [53]. ACE2 shown to function as receptor for SARS-CoV [54]. ACE2 is also the cellular entry point for the SARS-CoV-2 virus and SARS-CoV-2 has an even higher affinity than SARS-CoV for ACE2 [55]. The expression and distribution of ACE2 in the human body may indicate the potential routes of infection and the organs most targeted by SARS-CoV-2. ACE2 is differentially expressed in tissues and organs. High ACE2 expression is identified in 


\section{International Journal of Current Science Research and Review}

ISSN: 2581-8341

Volume 04 Issue 07 July 2021

DOI: 10.47191/ijcsrr/V4-i7-02, Impact Factor: 5.825

IJCSRR@ 2021

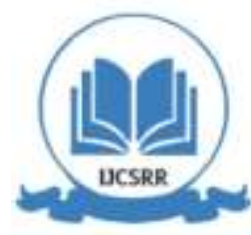

www.ijesrr.org

pulmonary alveolar cells, esophageal epithelial cells, absorptive enterocytes from the ileum and colon, cholangiocytes, myocardial cells, renal proximal tubular cells, bladder urothelial cells, and oral mucosal epithelial cells [56]. ACE2 expression and distribution change with age, and it is affected by several diseases. In particular, in order to provide a healthy metabo lism, ACE2 must be regulated in a balanced way (not too little and not too much) [53].

\section{CONCLUSION}

During the COVID-19 virus pandemic, Nanogold-Nanosilver Health Drinking Water succeeded to maintain immunity from participants who had comorbidities with diabetes mellitus and were affected by COVID-19. It is evidenced by data on the decrease in participants blood sugar levels while consuming Nanogold-Nanosilver Health Drinking Water during treatment. Besides, participants can stay safe from being exposed to COVID-19 during this activity, even though people with diabetes mellitus should have a greater chance of being infected with COVID-19 and worse complications when compared to sufferers in general. A drug with a combination of nanogold-nanosilver is a medicine for the future and the world.

\section{ACKNOWLEDGEMENT}

We give our gratitude to the Indonesian Ministry of Education and Culture for funding research on development research schemes with contract numbers 193/SP2H/LT/DRPM/2019 and B/21831/UN38.9/LK.04.00/2019.

\section{REFERENCE}

1. C. A. Glass, J. C. Cash, and J. Mullen, "Coronavirus Disease (COVID-19)," in Family Practice Guidelines, New York, NY: Springer Publishing Company, 2020.

2. World Health Organization, "WHO Coronavirus Disease (COVID-19) Dashboard," 2021. [Online]. Available: https://covid19.who.int/?gclid=CjwKCAjwnK36BRBVEiwAsMT8WJ3y00_BUzvrLsvbl3uthuoTH_Occ45gyEUbpYRyEq Azll3aZB6TYxoCcM0QAvD_BwE. [Accessed: 10-Jan-2021].

3. R. Gupta, A. Ghosh, A. K. Singh, and A. Misra, "Clinical considerations for patients with diabetes in times of COVID-19 epidemic,” Diabetes Metab. Syndr. Clin. Res. Rev., vol. 14, pp. 211-212, 2020, doi: 10.1016/j.dsx.2020.03.002.

4. J. Yang et al., "Prevalence of comorbidities and its effects in coronavirus disease 2019 patients: A systematic review and meta-analysis," Int. J. Infect. Dis., vol. 94, pp. 91-95, 2020, doi: 10.1016/j.ijid.2020.03.017.

5. World Health Organization, "Diabetes," 2021. [Online]. Available: https://www.who.int/health-topics/diabetes\#tab=tab_1. [Accessed: 12-Jan-2021].

6. World Health Organization, Global Report on Diabetes. France: MEO Design \& Communication, meomeo.ch, 2016.

7. A. K. Singh, R. Gupta, A. Ghosh, and A. Misra, "Diabetes in COVID-19: Prevalence, pathophysiology, prognosis and practical considerations," Diabetes Metab. Syndr. Clin. Res. Rev., vol. 14, no. 4, pp. 303-310, 2020, doi: 10.1016/j.dsx.2020.04.004.

8. Z. Wu and J. M. McGoogan, "Characteristics of and Important Lessons From the Coronavirus Disease 2019 (COVID-19) Outbreak in China," Jama, pp. 1239-1242, 2020, doi: 10.1001/jama.2020.2648.

9. P. Singh, Y. J. Kim, D. Zhang, and D. C. Yang, "Biological Synthesis of Nanoparticles from Plants and Microorganisms," Trends Biotechnol., vol. 34, no. 7, pp. 588-599, 2016, doi: 10.1016/j.tibtech.2016.02.006.

10. M. Bachelet, "Design of pH-responsive gold nanoparticles in oncology," Mater. Sci. Technol., vol. 32, no. 8, pp. 794-804, 2016, doi: 10.1179/1743284715Y.0000000090.

11. T. Taufikurohmah, I. G. M. Sanjaya, A. Baktir, and A. Syahrani, “Activity Test of Nanogold for Reduction of Free Radicals, a Pre-Assessment Utilisation Nanogold in Pharmaceutical as Medicines and Cosmetics," J. Mater. Sci. Eng. B, vol. 2, no. 12, pp. 611-617, 2012.

12. M. A. Syed and S. H. A. Bukhari, "Gold Nanoparticle Based Microbial Detection and Identification Muhammad,” J. Biomed. Nanotechnol., vol. 7, no. 2, pp. 1-9, 2011, doi: 10.1166/jbn.2011.1281.

13. S. R. Ahmed, J. Kim, T. Suzuki, J. Lee, and E. Y. Park, "Detection of Influenza Virus Using Peroxidase-mimic of Gold Nanoparticles†,", Biotechnol. Bioeng., pp. 1-19, 2016, doi: 10.1002/bit.25982.

14. T. Taufikurohmah, D. Winarni, A. Baktir, I. G. M. Sanjaya, and A. Syahrani, "Histology Study: Pre-Clinic Test of Nanogold in Mus Musculus Skin, at Fibroblast Proliferation and Collagen Biosynthesis," Chem. Mater. Res., vol. 3, no. 5, pp. 55-60, 2013.

15. L. A. Dykman and N. G. Khlebtsov, "Gold Nanoparticles in Biology and Medicine: Recent Advances and Prospects," Acta 


\section{International Journal of Current Science Research and Review}

ISSN: 2581-8341

Volume 04 Issue 07 July 2021

DOI: 10.47191/ijcsrr/V4-i7-02, Impact Factor: 5.825

IJCSRR@ 2021

Www.ijcsrr.org

Naturae, vol. 3, no. 2, pp. 34-55, Jun. 2011, doi: 10.32607/20758251-2011-3-2-34-55.

16. J. K. Schluesener and H. J. Schluesener, "Nanosilver: Application and novel aspects of toxicology," Arch. Toxicol., vol. 87, no. 4, pp. 569-576, 2013, doi: 10.1007/s00204-012-1007-z.

17. A. Hebeish, M. H. El-Rafie, M. A. El-Sheikh, and M. E. El-Naggar, "Nanostructural Features of Silver Nanoparticles Powder Synthesised through Concurrent Formation of the Nanosized Particles of Both Starch and Silver," J. Nanotechnol., pp. 110, 2013, doi: 10.1155/2013/201057.

18. J. L. Elechiguerra et al., "Interaction of silver nanoparticles with HIV-1," J. Nanobiotechnology, vol. 3, no. 6, pp. 1-10, 2005, doi: 10.1186/1477-3155-3-6.

19. S. BarathManiKanth et al., "Anti-oxidant effect of gold nanoparticles restrains hyperglycemic conditions in diabetic mice," J. Nanobiotechnology, vol. 8, no. July 2010, 2010, doi: 10.1186/1477-3155-8-16.

20. T. I. Shaheen et al., "Anti-diabetic assessment; in vivo study of gold and core-shell silver-gold nanoparticles on streptozotocin-induced diabetic rats," Biomed. Pharmacother., vol. 83, pp. 865-875, 2016, doi: 10.1016/j.biopha.2016.07.052

21. B. A. Katsnelson et al., "Comparative in Vivo Assessment of Some Adverse Bioeffects of Equidimensional Gold and Silver Nanoparticles and the Attenuation of Nanosilver's Effects with a Complex of Innocuous Bioprotectors," Int. J. Mol. Sci., vol. 14, pp. 2449-2483, 2013, doi: 10.3390/ijms14022449.

22. Y. H. Choi and H. K. Han, "Nanomedicines: current status and future perspectives in aspect of drug delivery and pharmacokinetics," J. Pharm. Investig., vol. 48, pp. 43-60, 2018, doi: 10.1007/s40005-017-0370-4.

23. L. Dyshlyuk, O. Babich, S. Ivanova, N. Vasilchenco, A. Prosekov, and S. Sukhikh, "Suspensions of metal nanoparticles as a basis for protection of internal surfaces of building structures from biodegradation," Case Stud. Constr. Mater., vol. 12, pp. 1-8, 2020, doi: 10.1016/j.cscm.2019.e00319.

24. H. Li and L. Rothberg, "Colorimetric detection of DNA sequences based on electrostatic interactions with unmodified gold nanoparticles," in Proceedings of the National Academy of Sciences of the United States of America, 2004, vol. 101, no. 39, pp. 14036-14039, doi: 10.1073/pnas.0406115101.

25. S. F. Ahmed, A. A. Quadeer, and M. R. McKay, "Preliminary Identification of Potential Vaccine Targets for the COVID-19 Coronavirus (SARS-CoV-2) Based on SARS-CoV Immunological Studies Syed," Viruses, vol. 12, no. 3, 2020, doi: 10.3390/v12030254.

26. S. Galdiero, A. Falanga, M. Vitiello, M. Cantisani, V. Marra, and M. Galdiero, "Silver Nanoparticles as Potential Antiviral Agents," Molecules, vol. 16, pp. 8894-8918, 2011, doi: 10.3390/molecules16108894.

27. S. S. Jeremiah, K. Miyakawa, T. Morita, Y. Yamaoka, and A. Ryo, "Potent antiviral effect of silver nanoparticles on SARSCoV-2," Biochem. Biophys. Res. Commun., vol. 533, no. 1, pp. 195-200, Nov. 2020, doi: 10.1016/j.bbrc.2020.09.018.

28. B. Nowack, H. F. Krug, and M. Height, " 120 Years of Nanosilver History: Implications for Policy Makers,” Environ. Sci. Technol., vol. 45, pp. 7593-7595, 2011, doi: 10.1021/es2017895.

29. R. Singla, S. Soni, V. Patial, and P. M. Kulurkar, "Cytocompatible Anti-microbial Dressings of S yzygium cumini Cellulose Nanocrystals Decorated with Silver Nanoparticles Accelerate Acute and Diabetic Wound Healing," Sci. Rep., vol. 7, no. 10457, pp. 1-13, 2017, doi: 10.1038/s41598-017-08897-9.

30. V. Vijayakumar, S. K. Samal, S. Mohanty, and S. K. Nayak, "Recent Advancements in Biopolymer and Metal NanoparticleBased Materials in Diabetic Wound Healing Management," Int. J. Biol. Macromol., vol. 122, pp. 1-52, 2018, doi: 10.1016/j.ijbiomac.2018.10.120.

31. Pemerintah Kota Surabaya, "Surabaya Lawan COVID-19," 2021. [Online]. Available: https://lawancovid-19.surabaya.go.id/visualisasi/graph. [Accessed: 12-Jan-2021].

32. A. A. Dayem et al., "The Role of Reactive Oxygen Species (ROS) in the Biological Activities of Metallic Nanoparticles," Int. J. Mol. Sci., vol. 18, pp. 1-21, 2017, doi: 10.3390/ijms18010120.

33. A. Majdalawieh, M. C. Kanan, O. El-Kadri, and S. M. Kanan, "Recent Advances in Gold and Silver Nanoparticles: Synthesis and Applications," J. Nanosci. Nanotechnol., vol. 14, pp. 4757-4780, 2014, doi: 10.1166/jnn.2014.9526.

34. R. Opris et al., "THE EFFECT OF SAMBUCUS NIGRA L. EXTRACT AND PHYTOSINTHESIZED GOLD NANOPARTICLES ON DIABETIC RATS,” Colloids Surfaces B Biointerfaces, vol. 150, pp. 192-200, 2017, doi: 10.1016/j.colsurfb.2016.11.033.

35. P. Ghosh, G. Han, M. De, C. K. Kim, and V. M. Rotello, "Gold nanoparticles in delivery applications," Adv. Drug Deliv. Rev., vol. 60, no. 11, pp. 1307-1315, 2008, doi: 10.1016/j.addr.2008.03.016.

36. G. K. Ferreira et al., "Gold nanoparticles alter parameters of oxidative stress and energy metabolism in organs of adult rats," 


\section{International Journal of Current Science Research and Review}

ISSN: 2581-8341

Volume 04 Issue 07 July 2021

DOI: 10.47191/ijcsrr/V4-i7-02, Impact Factor: 5.825

IJCSRR@ 2021

Www.ijcsrr.org

Biochem Cell Biol, vol. 93, no. 6, pp. 548-557, 2015, doi: http://dx.doi.org/10.1139/bcb-2015-0030.

37. M. Sengani and D. R. V, "Identification of Potential Anti-oxidant Indices by Biogenic Gold Nanoparticles in Hyperglycemic Wistar Rats," Environ. Toxicol. Pharmacol., 2017, doi: 10.1016/j.etap.2017.01.007.

38. M. Wang, S. K. Marepally, P. K. Vemula, and C. Xu, "Inorganic Nanoparticles for Transdermal Drug Delivery and Topical Application," Nanosci. Dermatology, pp. 57-72, 2016, doi: 10.1016/B978-0-12-802926-8.00005-7.

39. S. Roy, S. Shankar, and J. Rhim, "Melanin-mediated synthesis of silver nanoparticle and its use for the preparation of carrageenan-based anti-bacterial films," Food Hydrocoll., pp. 1-43, 2018, doi: 10.1016/j.foodhyd.2018.10.013.

40. A.-C. Burdusel, O. Gherasim, A. M. Grumezescu, L. Mogoantă, A. Ficai, and E. Andronescu, "Biomedical Applications of Silver Nanoparticles : An Up-to-Date Overview," nanomaterials, vol. 8, no. 681, pp. 1-25, 2018, doi: 10.3390/nano8090681.

41. S. Hamdan et al., "Nanotechnology-Driven Therapeutic Interventions in Wound Healing: Potential Uses and Applications," ACS Cent. Sci., vol. 3, pp. 163-175, 2017, doi: 10.1021/acscentsci.6b00371.

42. A. Sengottaiyan et al., "Synthesis and characterisation of Solanum nigrum -mediated silver nanoparticles and its protective effect on alloxan-induced diabetic rats," J. Nanostructure Chem., vol. 6, pp. 41-48, 2016, doi: 10.1007/s40097-015-0178-6.

43. H. Agarwal, S. V. Kumar, and S. Rajeshkumar, "ANTI-DIABETIC EFFECT OF SILVER NANOPARTICLES SYNTHESISED USING LEMONGRASS ( CYMBOPOGON CITRATUS ) THROUGH CONVENTIONAL HEATING AND MICROWAVE IRRADIATION APPROACH," J. Microbiol. Biotechnol. Food Sci., vol. 7, no. 4, pp. 371-376, 2018, doi: 10.15414/jmbfs.2018.7.4.371-376.

44. A. Badawi and S. G. Ryoo, "Prevalence of diabetes in the 2009 influenza A (H1N1) and the middle east respiratory syndrome coronavirus: A systematic review and meta-analysis," J. Public health Res., vol. 5, no. 733, pp. 130-138, 2016, doi: 10.4081/jphr.2016.733.

45. R. Muniyappa and S. Gubbi, "COVID-19 pandemic, coronaviruses, and diabetes mellitus," Am. J. Physiol. - Endocrinol. Metab., vol. 318, no. 5, pp. E736-E741, 2020, doi: 10.1152/ajpendo.00124.2020.

46. D. Ardigo, S. Valtuena, I. Zavaroni, M. C. Baroni, and R. Delsignore, "Pulmonary Complications in Diabetes Mellitus: The Role of Glycemic Control," Curr. Drug Targets Inflamm. Allergy, vol. 3, pp. 455-458, 2004, doi: 10.2174/1568010042634488.

47. L. Fuso, D. Pitocco, and R. Antonelli-Incalzi, "Diabetic lung, an underrated complication from restrictive functional pattern to pulmonary hypertension," Diabetes Metab Res Rev, 2019, doi: 10.1002/dmrr.3159.

48. S. Costantino et al., "Impact of Glycemic Variability on Chromatin Remodeling, Oxidative Stres , and Endothelial Dysfunction in Patients With Type 2 Diabetes and With Target HbA 1c Levels," Diabetes, vol. 66, pp. 2472-2482, 2017, doi: https://doi.org/10.2337/db17-0294.

49. I. A. A. El-azeem, G. Hamdy, M. Amin, and A. Rashad, "Pulmonary function changes in diabetic lung," Egypt. J. Chest Dis. Tuberc., vol. 62, pp. 513-517, 2013, doi: 10.1016/j.ejcdt.2013.07.006.

50. B. J. Philips, J.-X. Meguer, J. Redman, and E. H. Baker, "Factors determining the appearance of glucose in upper and lower respiratory tract secretions," Intensive Care Med, vol. 29, pp. 2204-2210, 2003, doi: 10.1007/s00134-003-1961-2.

51. A. Iqbal et al., "Effect of Hypoglycemia on Inflammatory Responses and the Response to Low-Dose Endotoxemia in Humans," J. Clin. Endocrinol. Metab., vol. 104, no. 4, pp. 1187-1199, 2019, doi: 10.1210/jc.2018-01168.

52. R. Rodriguez-gutierrez, J. G. Gonzalez-gonzalez, J. A. Zuñiga-hernandez, and R. G. Mccoy, "Benefits and harms of intensive glycemic control in patients with type 2 diabetes," BMJ, vol. 367, 2019, doi: 10.1136/bmj.15887.

53. R. Pal and A. Bhansali, "COVID-19, diabetes mellitus and ACE2: The conundrum," Diabetes Res. Clin. Pract., vol. 162, pp. 1-3, 2020, doi: 10.1016/j.diabres.2020.108132.

54. S. M. Bindom and E. Lazartigues, "The sweeter side of ACE2: Physiological evidence for a role in diabetes," Mol. Cell. Endocrinol., vol. 302, pp. 193-202, 2009, doi: 10.1016/j.mce.2008.09.020.

55. D. Wrapp et al., "Cryo-EM structure of the 2019-nCoV spike in the prefusion conformation," Science (80-. )., vol. 367, pp. 1260-1263, 2020, doi: 10.1126/science.aax0902.

56. H. Xu et al., "High expression of ACE2 receptor of 2019-nCoV on the epithelial cells of oral mucosa," Int. J. Oral Sci., vol. 12, no. 8, pp. 1-5, 2020, doi: 10.1038/s41368-020-0074-x.

Cite this Article: Fatimatuzzahro, Titik Taufikurohmah (2021). The Effect of Nanogold-Nanosilver to Boost Immunity of People Affected by COVID-19 with Comorbidities of Diabetes Mellitus. International Journal of Current Science Research and Review, 4(7), 625-632 